\title{
Radiotherapy and Immunity - A Mini Review
}

\author{
Rosangela Correa Villar \\ Department of Radiation Oncology, University of Sao Paulo, Medicine School
}

Brasil

\section{Introduction}

Slavin et al. in [1976], were the first to found that rejection of skin and heart allograft was greatly delayed in rodents treated with Total Lymphoid Irradiation (TLI). Since 1980, the immunosupression of TLI has been applied in transplants and autoimmune diseases. However, the development of immunosuppressive drugs decreased the use of radiotherapy for immunosuppressive finality except for the use of total body irradiation (TBI) or TLI as myeloablative treatment before bone marrow transplantation

The mechanism by which TLI-treated patients have a graft prolongation is not entirely understood. During many years of its use many changes has been observed specially in lymphocytes counts. The majority of the studies, however, were done without modern techniques to characterize the fate of different subtypes of lymphocytes and is difficult to compare the results. The majority of the studies has been done in vitro and in regimes using TBI and bone marrow transplants. There is some evidence that suppressor T-cells might be involved in the long term maintenance of allografts in these patients [Gray et al, 1989]. TLI provokes a more pronounced impairment of T-dependent immunological functions, as measured with phytohemaglutinin- (PHA), concanavalin A- (Con A), and pokeveedinduced (PWM) blastogenesis than does conventional immunosuppression. The more profound changes in the balance between T helper and T suppressor cells after TLI are also associated with a more pronounced suppressor cell activity, as measured with different functional suppressor cell assays. [Fergunson et al, 1981; Waer et al, 1987]. The TLI seems to produce an "amnesic state" and the autoantigens cannot be recognized by the host anymore. In the past, radiation therapy had traditionally been viewed as immunosuppressive (Cole, 1986; James et al., 1989; Wasserman et al., 1989). Lymphocyte radiosensitivity is well established and remains the dominant explanation for this effect. However, substantial evidence suggests more varied effects of radiation on the immune system, prompting the recharacterization of radiation as 'immunomodulatory' rather than immunosuppressive (McBride et al., 2004).

Ionising radiation induces diverse effects on cell survival, apoptosis, proliferation and differentiation depending on the dosage and target cell (Jonathan et al. 1999). High dose of radiation often results in massive DNA damage that involves double-strand breaks and subsequent cell death. Low dose of irradiation induces reactive oxygen species (ROS) and the activation of specific intracellular signaling pathways and transcription factors leading to proliferation and differentiation of target cells (Kasid et al. 1996, Lander et al. 1997, Finkel 1998). Therefore, irradiation can modulate immune response via its variable effects on immune cell survival and differentiation (Shankar et al. 1999, Rho et al. 2004, Liu 2007, Shan et al.2007). 
The immune system responds to ionizing radiation with distinct characteristics depending on multiple factors such as dose and dose rate, tissue and cell types. Overall, immune cells are susceptible to radiation-induced damage and readily undergo apoptosis in response to small doses of radiation. Cellular apoptosis is critically regulated by various intracellular and extracellular signaling mechanisms. CD95 (Apo-1/Fas) is a homotrimeric tumour necrosis factor receptor (TNFR) family member characterised by the presence of a death domain in its cytoplasmic tail. CD95-mediated apoptosis is an important process with enormous physiological and pathophysiological impact and cell-type-specific features. CD95 molecules have been implicated in the maintenance of self-tolerance and T-cell homeostasis by transmitting apoptotic signals to repeatedly activated antigen-specific $\mathrm{T}$ cells, as well as to antigen-presenting dendritic cells (DCs) and activated B cells. (Schu" tze et al. 2008). For example, It has been described that Treg maintain immunological tolerance by suppression of autoreactive $\mathrm{T}$ cells but it was also shown that low dose total body irradiation (LTBI) selectively decreased the proportion and absolute number of Treg and enhanced antitumor immunity in murine model. It occurs because Treg displaying much higher apoptotic baseline and apoptosis-related proteins are more radiosensitive than its effector counterpart CD4pCD257T cells ( Mendge et al, 2011) An important finding to help explain the immune 'stimulating' effect of low dose irradiation is the differential impact on Treg vs. CD4p CD257 cell population. These relevant findings appoint to the hypotheses that the net balance for the immune system may be a relative decrease in Treg-mediated suppression and a net increase in effector T cell activity. Similar effect was confirmed in invivo that LTBI is a very attractive adjuvant strategy to enhance overall cancer immunotherapy or vaccine responses (Liu et al.2010). Other possible mechanisms of immune enhancement are elimination of suppressor cells as Treg and myeloid suppressor cells and augmentation of the immune response including natural killer (NK) cells, B cells and T cells activation, costimulatory molecules upregulation, IFNg and IL-2 production and release, and enhanced proliferative activity of lymphocytes to mitogenic stimuli ( Belka et al, 1999; Hashimoto et al, 1999; Safwat 2000a; 2000b; Liu et al, 2001; Kipnis et al, 2004; Jin et al, 2007; Shan et al, 2007)

Although the effects of radiation on the survival of lymphocytes have been extensively studied in vitro, a correlation of the frequency of radiation-induced apoptosis in human peripheral blood lymphocytes during TLI have not previously been performed. In 2008 we published the clinical results of a protocol using TLI plus immunosuppressive agents to prevent recurrence after renal transplant in patients with focal and segmental glomerulosclerosis (FSGS) (Villar et al, 2008). This disease presents with early recurrence after renal transplants and an involvement of the immune system has been implicated in its pathogenesis. During the study the purpose was also to investigate the changes in peripheral blood monocyte and lymphocyte subpopulations and the role of the in vivo induction of apoptosis in patients undergoing TLI pre renal transplant (TX) (unpublished data). It was a very rare opportunity to study in vivo the immunosuppressant effect caused by TLI during each week of the treatement in patients that had not received any immunosuppressive drug or chemotherapy before. We studied 9 patients and they were treated with aggressive immunosuppressive treatment associating TLI with the drugs mycophenolate mofetil (MMF), prednisone (PRED) and cyclosporine (CsA) commonly used in conventional immunosuppressive treatments. TLI were performed as described in Villar et al, 2008. Immunophenotyped peripheral blood $\mathrm{T}$ and $\mathrm{B}$ lymphocyte subsets and monocytes were performed before treatment (control) and followed during each week of 
TLI (after each 9 Gy), on TX's day and after TX (30,60 and 90 days) using flow cytometry. The percentages of T-helper, T-suppressor, B-lymphocytes and monocytes/macrophages cells, were determined on the cells in the lymphogate. Mitogen stimulation tests in lymphocytes culture using phytohemaglutinin (PHA) and pokeweed mitogen (PWM) were performed before and after completion of TLI, at the TX day and at 1 month interval up to three months post-transplantation.

\subsection{Isolation of lymphocytes and detection of apoptosis}

The in vivo radiation-induced apoptosis in lymphocytes was investigated in blood samples of 9 patients before TLI, pre and pos-hemodyalisis (controls 1 and 2) and $6 \mathrm{~h}$ and 24h after the first and the second fraction of TLI and 6h after each 9 Gy until the end of TLI. The observation of apoptosis on freshly blood samples ( 2 patients) were insignificant then in the others (7 patients), we decided to observe the commitment to apoptosis of the lymphocytes irradiated in vivo after $72 \mathrm{~h}$ in cell culture with and without mitogen (PHA) using an ex vivo test. After the cells were kept in culture they were assessed for binding of Annexin by resuspending $2 \times 10^{5} \mathrm{cel} / 100 \mu \mathrm{l}$ and subsequently by incubating with $10 \mu \mathrm{l}$ Annexin V-FITC for 30min. In order to distinguish between apoptotic (Annexin V+/PI-) and secondary necrotic (Annexin $\mathrm{V}+/ \mathrm{PI}+)$ cells, $10 \mu \mathrm{l}$ of propidiun iodeto (PI) $(2 \mu \mathrm{g} / \mathrm{ml})$ was also added before analyzing on a Coulter Epics XL-MCL flow cytometer. Two-colour flow-cytometric analyses were performed on a FACSort. A gate was put on Annexin V + (green) cells and a backgating performed on the scatter plot in order to discriminate optimally platelets and debris from smaller apoptotic cells with exclusion of monocytes (increased side scatter). In cells with a damaged membrane PI cannot be excluded anymore and a red fluorescent signal was observed indicating secondary necrotic cells. The results were expressed as percentage of apoptotic cells in 10.000 cells counted in the pre-determined window. All the results were expressed as the percentage of the pre-treatment value. Statistical analysis was performed comparing the values before and after treatment (Friedman`s ANOVA - $\mathrm{p} \leq$ 0.05). We observed significant reduction of all parameters analysed after treatment. Leukocytes decreased 55\%, lymphocytes had a reduction of $60 \%, 70 \%$ and $97 \%$ for CD3/CD4, CD8 and CD19, respectively, at the transplant's day $(p<0,05)$ The statistical analysis showed a significant decrease since the first week of TLI $(p<0,05)$. The steep decrease for T cells was not significantly different between CD4 and CD8, but the decrease of B-cells was significantly more important than T-cells (fig.1). The decrease observed in CD14 cells was not significant $(p=0,569)$. Lymphocytes proliferative activity decrease $60 \%$ (with PHA) and 67\% (with PWM) after TLI. The PWM response was less expressive ( $\mathrm{p}=$ $0,09)$, statistical analysis showed reduction significantly maintained after TX only with PHA $(\mathrm{p}=0,009)$ (fig 2,3).

There was significant increase of apoptosis in vivo in peripheral blood lymphocytes (PBL) in the beginning of TLI, ( $6 \mathrm{~h}$ after first fraction of TLI) and necrosis at the end of TLI (10 and 15 fractions of TLI) (fig. 4,5). The phenomenon (apoptosis) was significantly increased by PHA stimulus (fig.6).

In our experience TLI provide important immunosuppresion with a significant fall in $\mathrm{T}$ and B lymphocytes and functional response to PHA. The B lymphocytes were the more radiosensitive and the monocyte the most radioresistant cells. No significant differences between T-helper and T-supressor/cytotoxic cells were observed.TLI induced significant increase of apoptosis in vivo in PBL after low doses and necrosis after high doses of TLI. 

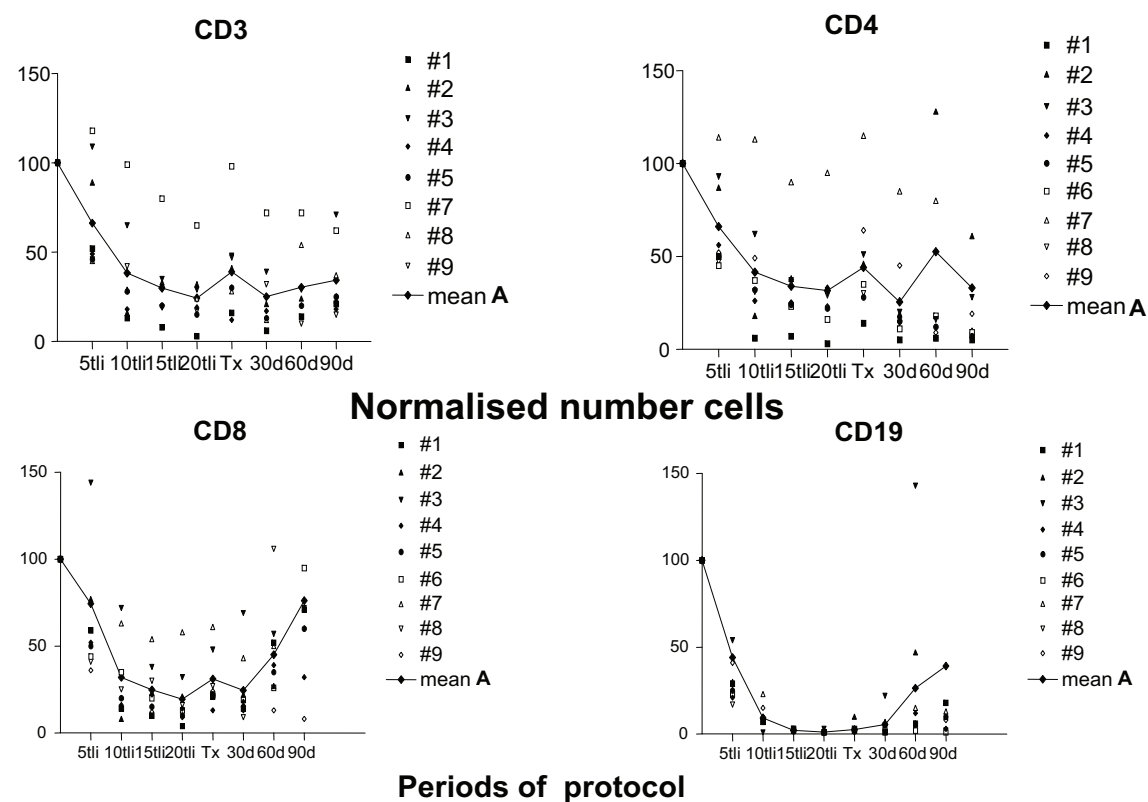

Fig. 1. Response of CD3, CD4, CD8, CD19 lymphocytes during radiotherapy and after transplant. The results were normalized to the values obtained before the treatment and plotted against the equivalent period of evaluation. A mean time-response curve resulting from statistical analyse to the data of all patients (mean A). Individual patients results are indicated on the figures

MONOCYTES

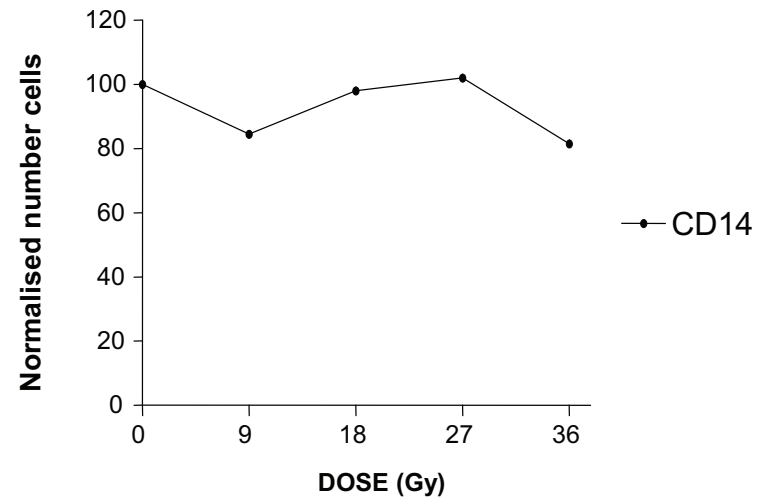

Fig. 2. Response of monocytes (CD14) with dose (Gy) in the nine (9) patients. The results were normalised to the values obtained before the start of the TLI and plotted against the equivalent period of the irradiation (first to fourth week). 


\section{Lymphocytes proliferative activity}

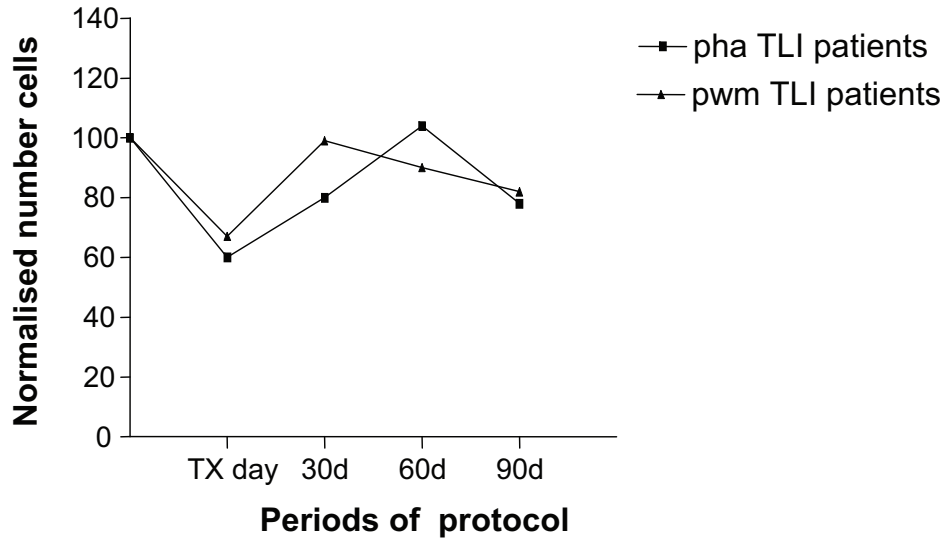

Fig. 3. Lymphoproliferative activity of 9 patients during the periods of protocol: control, after TLI (day of TX), 30, 60 and 90 days after TX. PHA = lymphocytes culture with phitohemaglutinin mitogen stimulation. $\mathrm{PWM}=$ lymphocytes culture with pokeweed mitogen stimulation

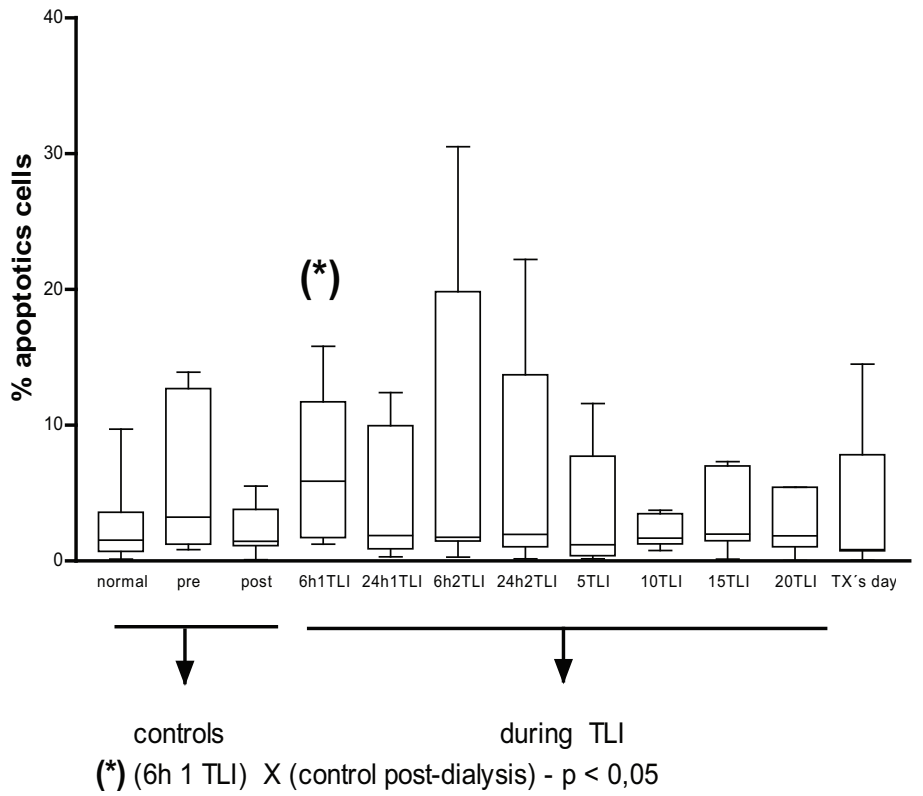

Fig. 4. Percentagem of apoptotic cells (Annexin+) observed in culture of lymphocytes without PHA. Results of controls (normal subjects, patients pre and post-dialysis and before TLI) , patients during TLI and on TX's day 


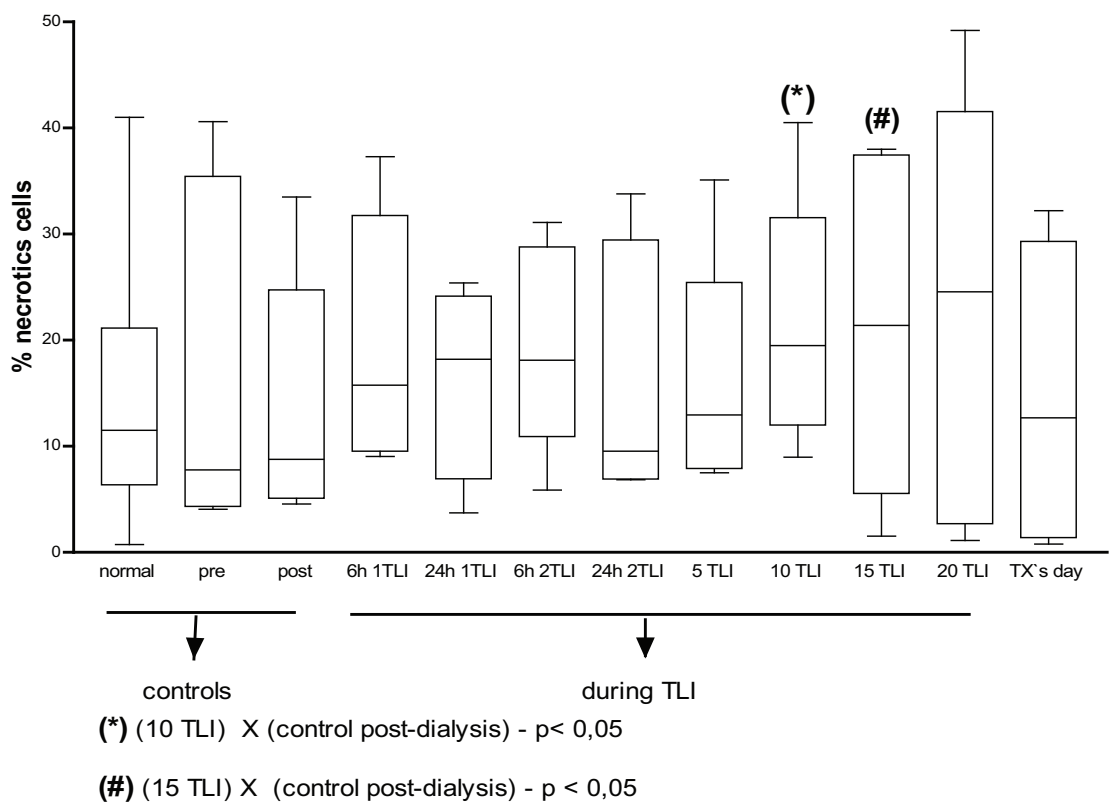

Fig. 5. Percentagem of necrotic cells $(\mathrm{Pi}+)$ observed in culture of lymphocytes without PHA. Results of controls (normal subjects, patients pre and post-dialysis and before TLI), patients during TLI and on TX's day. Necrotics cells increased at the end of TLI

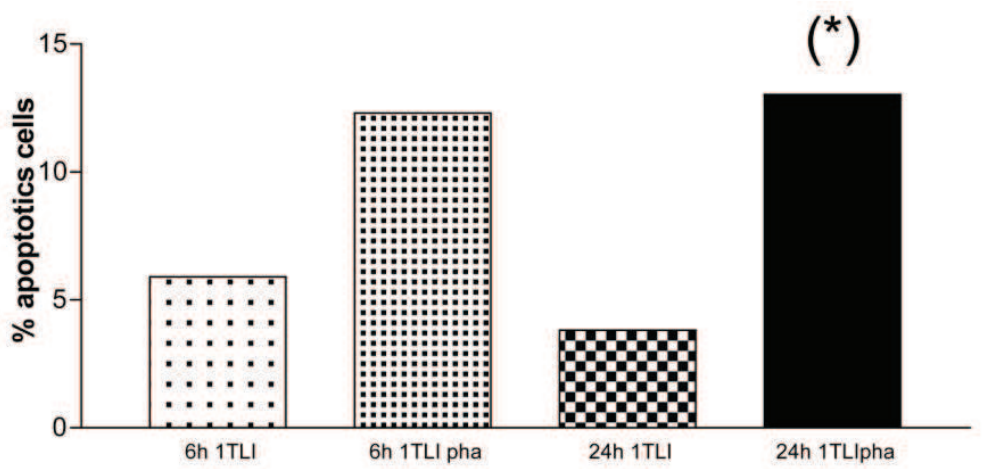

$\because 6$ after 1 TLI

[DI 24h after $1 \mathrm{TLI}$

24h after $1 \mathrm{TLI}$ with pha

\section{4h 1TLI pha X24 1TLI $\left(^{*}\right)-p<0,05$}

Fig. 6. Comparative analyse of percentagem of apoptotics cells observed in the periods of $6 \mathrm{~h}$ and $24 \mathrm{~h}$ after first fraction of TLI in culture of lymphocites with and without PHA.The percentagem of apoptosis was higher in the presence of PHA 


\section{Mini review}

Lymphocyte radiosensitivity is well established and remains the dominant explanation for the immunosuppressive effect of radiotherapy. However, substantial evidence suggests more varied effects of radiation on the immune system, prompting the re-characterization of radiation as 'immunomodulatory' rather than immunosuppressive (McBride et al., 2004). The effect of radiotherapy in microenviroment, cytokines, gene expressions and the importance of the dose in the immunossuprressive effect has emerging as new and important concepts. The use of the immunomodulatory effect of radiation in oncology has been pointed as a new perspective and its participation has again increasing in transplants tolerance and in treatment of autoimmune diseases. In the next pages we describe the new and important concepts recently acquired in radiotherapy and immunity

\subsection{The role of radiation}

\subsubsection{Immunomodulatory effects of radiation}

Increased expression of proinflammatory cytokines, including TNF-a and IL-1b following radiation has been reported by some authors (Hallahan et al.,1989; Ishihara et al., 1995; Nemoto et al., 1995). These observations suggest a potential role for radiation in signaling 'danger' and, perhaps, in the activation of antigen presenting cells (McBride et al., 2004). However, studies aimed at determining the effects of radiation on antigen-presenting cell phenotype, cytokine expression and function have been contradictory. While alterations in dendritic cells (DC) phenotype have been demonstrated infrequently (Cao et al.,2004), a number of investigators have noted changes in the cytokine secretory profile and function of DCs following irradiation. For example, Shigematsu et al. (2007), reported enhanced expression of IL-2, IL-12 and IFN-g by irradiated DCs and it was correlated with greater Tcell proliferation compared to non-irradiated DCs. In contrast, Merrick et al. (2005) reported decreased IL-12 production and impaired naive T-cell priming by irradiated compared to non-irradiated DCs. These contradictory findings may be attributable to the different irradiation strategies and models utilized in these studies. The effect of radiation on DC antigen presentation also remains controversial with a number of studies suggesting significant modulation of, or no effect on, T-cell stimulatory capacity. Interestingly, Liao et al. (2004) reported impaired T-cell priming against endogenously processed antigen and enhanced priming against exogenous peptide pointing to a more complex interplay between radiation and DC function. A number of factors may explain why the consistent characterization of immune responses to radiation remains elusive including differences in radiosensitivity or reactivity of different cell and tissue types, and dose-dependent effects. For example, the dose effect has been explored in a number of studies, some of which suggesting that lower doses of radiation have a greater potential to enhance immune responses (Hashimoto et al., 1999; Cao et al., 2002; Shigematsu et al., 2007)

\section{Irradiation and transplants}

Recently, the approach of combined organ and hematopoietic cell transplantation has been successfully applied to tolerance induction in humans (Fudaba el al., 2006; Scandling et al., 2008; Kawai et al., 2008). Conditioning regimens used to achieve mixed chimerism and tolerance include lethal and sublethal total body irradiation (TBI) with or without thymic irradiation and anti-T cell antibodies (Ildstad \& Sachs 1984; Kawai et al., 2002; Stykes 2001), 
TLI with and without anti-T cell antibodies (Slavin et al., 1976; Slavin et al., 1978; Slavin et al, 1977; Scandling et al., 2008 ;Hayamizu et al, 1999; Lan et al, 2000; Higuchi et al, 2002), costimulatory blockade with or without rapamycin therapy or cytoreduction (Wekerle et al, 2000; Durhan et al, 2000; Lambert et al., 2002;Graca et al., 2006), injection of naturally occurring CD4+CD25+ Treg (nTreg) cells combined with radiation cytoreduction (Golshayn et al., 2007; Wood \& Sakaguchi, 2003), and chemical cytoreduction combined with thymic irradiation, and anti-T cell antibodies (Fudaba et al, 2006; Kawai et al 2008,).

Although central and peripheral clonal deletion in chimeras can explain the lack of reactivity of host immune cells to donor alloantigens (Stikes 2001; Wekerle et al, 1998), host regulatory $\mathrm{T}$ cells that remain after cytoreduction or that are injected after cytoreduction can also play an important role in the engraftment of the donor organ and hematopoietic cells (Higushi 2002, Golshayn et al, 2007; Wood \& Sakaguchi 2003).

In the mixed chimera and tolerance induction model with TLI, anti-thymocyte serum (ATS), and bone marrow transplantation, tolerance is dependent on the residual host natural killer (NK) T cells. However,CD4 regulatory T cells, (Tregs) and nTregs induced from CD4+CD25- $\mathrm{T}$ cell precursors (iTregs) have been shown to play an important role in promoting tolerance to allografts in both chimeric and non-chimeric mouse models (Lambert et al., 2002,Chai et al, 2005,Graca et al., 2002, Sakaguchi, 2005, Kang et al, 2007). Nador et al, 2010 has been studying the role of residual host Tregs in the mixed chimera model using TLI and ATS conditioning. They demonstrated the requirement for host Tregs selectively depleting these cells pretransplant with a single injection of anti-CD25 mAb. The experiment results showed that deficiency in either NK T cell or Tregs prevents chimerism and tolerance in the TLI and ATS model. This lymphodepletive-conditioning regimen facilitated tolerance by altering the balance of host $\mathrm{T}$ cell subsets to markedly favor the NKT cells and Tregs over alloreactive host naïve (CD62LhiCD44lo) T cells. Therefore, the changes in the balance of regulatory and naïve $\mathrm{T}$ cell subsets and their contributions to graft acceptance or rejection using a TLI and ATS conditioning regimen is the responsible to induce mixed chimerism and tolerance after combined heart and bone marrow transplantation (Hayamizu et al., 1999; Lan et al., 2000; Higuchi et al., 2002).

It was demonstrated that one day after the completion of TLI and ATS conditioning (time point of donor bone marrow infusion) there was a marked increase in the ratio of CD4+ CD25+Foxp3+ Treg cells and NKT cells to naïve conventional T cells. The change in the balance of $\mathrm{T}$ cell subsets is best explained by their differential resistance to radiation induced cell death due to differential expression of the anti-apoptotic protein, Bcl-2, as reported previously (Yao et al., 2009). Nador et al, 2010 showed thatp53-/- mice had no change in the balance after TLI. T cell proliferation and thymic generation of $\mathrm{T}$ cells play a minimal role whereas the p53/Bcl-2 apoptotic pathway plays the dominant role in the changes (Yao et al, 2009). The considerable resistance of Treg cells to apoptosis induced by ATS as compared to conventional $\mathrm{T}$ cells has been reported to be due to high levels of expression of the antiapoptotic protein, BCLXL (Ninamimura et al, 2006). It is of interest that the altered balance of $\mathrm{T}$ cell subsets favoring Treg and NKT cells returned to normal about 6 weeks after conditioning, and by that time the stable mixed chimeras are tolerant to the heart allografts due to clonal deletion (Higuchi et al, 2002).

The relationship between NKT cells and Tregs in responses to alloantigens has been reported recently (Pillai et al, 2009). Naïve but not memory phenotype CD4+ T cells from untreated mice show alloreactivity in the MLR, and alloreactivity by conventional $\mathrm{T}$ cells in 
the MLR is suppressed by Treg cells at a 1:1 ratio (Dutt et al., 2007; Schiopu, A. \& Wood, 2008). The changed ratio of these cells on day 1 was likely to have prevented the hosts from rejecting bone marrow and heart allografts acutely. In another experiment, the ability of naïve and memory phenotype T cells from untreated BALB/c mice to reject C57BL/ 6 heart allografts was compared by transferring equal numbers of sorted cells to immunodeficient RAG-2-/- BALB/ c hosts bearing the grafts. Whereas the naïve cell injection resulted in rejection of all grafts, the memory phenotype cell injection obtained from donors that had not been exposed to alloantigens resulted in no rejection over a 100-day observation period. In conclusion, the TLI and ATS tolerance induction model requires both regulatory NKT cells and Tregs for graft acceptance. Tolerance is promoted by profound but transient changes in the balance of regulatory and naive $\mathrm{T}$ cells of host origin favoring the regulatory cells. (Nador et al, 2010)

\section{Irradiation and self-reactive immune response}

CD4 regulatory $\mathrm{T}$ cells (Tregs) are the main effectors of immunological tolerance in adult life. Several studies have indicated that quantitative and qualitative abnormalities of regulatory Tregs contribute to the pathogenesis of autoimmune diseases as collageninduced disease arthritis (CIA) (Morgan et al, 2003; Morgan et al, 2005) and in a spontaneous model of Rheumatoid Arthritis (RA).(Sakaguchi et al, 2003) There is evidence that the local proinflammatory environment is fundamental in imparting a Treg defect, because the treatment with anti-tumour necrosis factor (TNF) a may restore their function by generating transforming growth factor (TGF) $\beta$ producing Tregs.(Nadkarmi et al, 2007). Therefore, generating functionally effective Tregs may provide an effective approach for the treatment of collagen-induced disease.

The adoptive transfer of Tregs can be efficacious in the treatment of autoimmune diseases in preclinical models,(Tang Q, 2004) but the major limitation of such a strategy is that, in order to obtain a dose sufficient for clinical use, Tregs need to be expanded in vitro with implications on their functionality (Hoffman et al, 2009). An alternative strategy is to increase the number of Tregs by exploiting the selective advantage of Tregs over conventional $\mathrm{T}$ cells during homeostatic reconstitution following cell ablative treatments (Cox et al., 2005; Nadal et al., 2007). It was previously reported that even non-myeloablative doses of irradiation are sufficient to determine a selective retention/expansion of Tregs capable of producing an immunosuppressive activity against donor haematopoietic antigens, thus facilitating their engraftment (Weng et al, 2007). Therefore, one very possible hypothesis is that partial myeloablation could also generate the conditions to control autoimmune diseases.

Myeloablative regimens have successfully been used for the treatment of severe forms of autoimmune arthritis (Dazzi et al.; 2007) whereby the consequent haematopoietic reconstitution is associated with a comprehensive renewal of the T cell repertoire (Murano et al, 2005). The major drawback of these approaches is toxicity. Mild myeloablation appears to be sufficient to modulate pathogenic immune responses and produce beneficial effects on CIA (Nakatsukasa et al, 2008) but the mechanisms remain to be clarified.

Weng et al., 2010 demonstrated that low-dose irradiation ameliorates CIA at the time of disease induction and if used when clinical signs of the disease are detectable. They established a causative relationship between the therapeutic efficacy of irradiation and Treg 
mediated tolerance. Irradiation induced immune tolerance to the immunizing collagen through modalities that require the presence of Tregs. The therapeutic activity is associated with the development of Treg immunosuppressive activity and the in vivo depletion of Tregs prevents the beneficial effects of irradiation.

Tregs selectively survive myeloablative regimens and undergo a marked expansion while retaining their functional activity (Bayer et al., 2009). The same mechanisms might account for the therapeutic efficacy of autologous BM transplantation in autoimmune arthritis (Roord et al., 2008). In a proteoglycan-induced arthritis, the conditioning of recipient mice with a lethal irradiation dose (7.5 cGy) and subsequent syngeneic BM transplantation significantly reduced the severity of arthritis. This study observed an increment in the proportion of CD4CD25 $\mathrm{T}$ cells and the clinical improvement was prevented if recipient mice received anti-CD25 depleting antibodies 1 week after the transplant. In contrast to other results, the investigators did not observe any effect if anti-CD25 antibodies were given on the day of the transplant. The disparity should be ascribed to the different intensity of the conditioning regimen ( 7.5 cGy vs 4 cGy) that delayed Treg homeostatic reconstitution as demonstrated by the delayed peak of Treg expansion following the myeloablative dose (Bayer et al, 2009).

The transient nature of the therapeutic effect induced by low-dose irradiation in the CIA model can result from the contribution of various factors. Firstly, the Tregs that are proportionally expanded following the non-myeloablative regimen are of recipient origin and, because of the rapid expansion kinetics, of the memory type. Their effect could be less durable and/or less potent than the naive Tregs that are generated at a later stage during the haematopoietic reconstitution following full myeloablation (Roord et al., 2008). However, to our knowledge there is no evidence of such at difference in the activity of different Treg subtypes and it is more likely that the magnitude of myeloablation differently influences the duration and thus the efficacy of the Tregs proportional increment (Weng et al., 2007; Laylor et al, 2005). The quantization of CD4CD25FoxP3+ following low-dose irradiation indicated that the percentage of Tregs increased at 12 days and, although less so, also remained elevated a week later. However, when we enumerated the absolute values, the numbers of CD4CD25FoxP3+ were much reduced as compared to CIA controls. Since the absolute number of CD4FoxP3-T cells, which contain the fraction responsible for mediating the disease, was equally reduced, it is the resulting change in the ratio between effectors and Tregs that should account for the therapeutic effect. The characterization of the effector cells in treated mice suggests that the dose of irradiation used did not affect the proportion of IL17 producing T cells. Since IL17 has been suggested to play an important role in RA and CIA (Fugimoto et al, 2008), it appears that neither irradiation nor the proportional Treg expansion is sufficient to interfere with IL17 production. Although this could justify the incomplete therapeutic effect, the levels of T helper 17 cells (Th17) in peripheral lymphoid tissues do not correlate with their levels in the injured tissues. It has been reported that anti-TNFa treatment, despite its ability to prevent Th17 in the joints increases their numbers in draining LNs.(Notley et al., 2008) We also observed that the numbers of IFN $\gamma$-producing cells are reduced in the irradiated animals. While reducing the inflammatory activity, the inhibition of IFNY production also limits the potential to convert effector to FoxP3+ cells.(Xiao et al., 2008) The interpretation of the data is complicated by the fact that the pathogenic or protective effects of these cytokines are dependent on the timing of their production.(Lohr et al., 2006) The evidence provided the rationale to exploit the 
selective Treg activation induced by partial immunoablation for the treatment of autoimmune diseases. Further studies are however warranted to improve the duration of the therapeutic efficacy (Weng et al., 2010).

\section{Radiotherapy and immunomodulation in cancer}

Radiation is commonly used as a method of decreasing lymphocyte numbers via cytotoxicity for the purpose of bone marrow transplantation (BMT). CD25pCD4p regulatory $\mathrm{T}$ cells (Treg) comprise $5-10 \%$ of the circulating CD4p $\mathrm{T}$ cell population and suppress immune responses. A large body of experimental data suggests an essential role played by these cells in self-tolerance, transplantation, allergy and tumor/microbial immunity (Wing et al. 2006). Currently, many investigators are pursuing strategies to modulate the function or the number of Treg, which may offer a means to regulate host immunity for therapeutic effect in autoimmune diseases and cancers (Zou 2006). However, previous investigators have also suggested that low-dose whole-body irradiation (LTBI) results in immune enhancement in the treatment of chronic lymphocytic leukemia (CLL) and lymphoma (Safwat 2000a, 2000b). Accumulating evidence shows that irradiation influences the phenotype and function of immune cells (Cao et al. 2004, 2009, Reuben et al. 2004, Merrick et al. 2005). For example, Cao et al, showed that irradiation inhibited proliferation and suppressive ability of Treg with dose-dependent decrease of FOXP3 expression (Cao et al. 2009). A differential radiosensitivity and apoptosis-related proteins expression exist at varying doses of radiation between human Treg and effector T cells. LTBI is successful in inducing long-term remissions and has been shown to be as effective as the chemotherapy to which it has been compared in lymphoma (Safwat 2000a). However, the mechanism of this effect is unknown. The efficacy of LTBI could be partly attributed to a radiation-induced immune enhancement rather than to direct killing of tumor cells by radiation. This type of immune enhancement could be induced by two mechanisms: a differential elimination of the suppressive $\mathrm{T}$ subset of lymphocytes or an augmentation of the immune response through direct and/or indirect stimulation of $\mathrm{T}$ lymphocytes. RT can also theoretically enhance anti-tumor immunity via increasing the expression of tumor-associated antigens, inducing immune-mediated targeting of the tumor stroma, and diminishing regulatory $\mathrm{T}$ cell activity. Recent evidence suggests that RT may also activate effectors of innate immunity through Toll-like receptor (TLR)-dependent mechanisms, thereby augmenting the adaptive immune response to cancer (Roses et al. 2008). Thus RT can be better-characterized as having immunomodulatory properties that can allow its use as adjunct to immunotherapy (McBride et al. 2004).

\section{Enhancement of antitumor effectors mechanisms}

The efficacy of radiation therapy in the treatment of many tumor types is well established. While radiation induced tumor regression is largely the result of directed damage to radiosensitive tumor cells, evidence points to a number of additional immune-mediated mechanisms. Suppressor populations of $\mathrm{T}$ cells may be more radiosensitive than their effector counterparts and, conversely, tumor-specific effector T cells may be relatively radioresistant (North, 1986; Dunn and North, 1991). This notion, as it relates to contemporary definitions of regulatory T cells (Tregs), has not been extensively explored. However, one recent study implicated Treg depletion in the enhanced efficacy of adoptive T-cell 
immunotherapy for transplanted melanomas following whole-body irradiation in a murine model (Antony et al., 2005). Enhanced functionality of adoptively transferred $\mathrm{T}$ cells following radiation induced lympho-depletion has also been linked to increased availability of homeostatic cytokines (Wrzesinski et al., 2007). A number of studies have measured the effects of low-dose total-body irradiation on the relative size of T-cell subpopulations and expression of cytokines associated with T-cell activation. In one report, low dose irradiation following transplantation of a hepatoma cell line in a rat model resulted in an increased proportion of CD8-positive splenocytes, increased numbers of tumor infiltrating lymphocytes, increased TNF-a and IFN-g expression and decreased TGF-b expression This response correlated with a reduction in metastases (Hashimoto et al., 1999). Another study demonstrated an increased CD4:CD8 T cell ratio, and decreased expression of TGF-b and VEGF following low-dose total body-irradiation, which correlated with delayed tumor growth in mice transplanted with the Lewis lung carcinoma cell line (Miller et al., 2003). The so-called 'abscopal effect', whereby radiation results in reduced tumor growth outside the direct radiation field, suggests radiation-induced immune-mediated mechanisms. The fact that this effect may be enhanced with Fms-like tyrosine kinase receptor 3 ligand (Flt-3L), a stem cell mobilizing factor that augments the number of circulating DC precursors, in immunocompetent mice and abrogated in T-cell-deficient mice lends additional support to this contention (Demaria et al., 2004).

\section{Stromal effects}

Radiation may induce immune-mediated targeting of tumor stroma. Antigen released following tumor irradiation may be presented by stromal cells for subsequent destruction by CTLs. This mechanism was recently demonstrated by Zhang et al. (2007) in experiments utilizing immunodeficient mice given tumor transplants. Only the combination of irradiation and adoptive transfer of CTLs resulted in tumor regression. This regression correlated with increased expression of tumor-specific peptide-MHC complexes as delineated using a tumor antigen/MHC complex-specific TCR tetramer. Direct effects of radiation on the stroma may play a role in enhancing immune-mediated tumor regression as well. Induced modulation of the expression of adhesion molecules, such as accumulation of P-selectin in the lumen of tumor vasculature, may enhance infiltration of immune effectors into the tumor stroma (Hallahan et al., 1998; Hallahan and Virudachalam, 1999). Enhancement of tumor antigen recognition Induction of antitumor immunity by radiation may result from enhanced tumor antigen recognition. Irradiation induces tumor cell apoptosis, or necrosis secondary to vascular injury (Acker et al., 1998). Subsequent phagocytosis of apoptotic bodies by DCs and initiation of antitumor T-cell responses through cross presentation may ensue if DC maturation signals are concomitantly present. A number of studies have suggested that necrosis, but not apoptosis, is associated with DC maturation signals (Basu et al., 2000; Sauter et al., 2000) However, more recently evidence that some apoptotic pathways do induce DC maturation and antitumor immunity has emerged (Scheffer et al., 2003). Sublethal irradiation of tumors may also result in enhanced expression of surface molecules recognized or targeted by immune effectors, as is suggested by studies demonstrating increased expression of the MHC class I antigen, H-2D, by melanoma cells (Hauser et al., 1993) and tumor associated antigens including carcinoembryonic antigen by gastric adenocarcinoma cells (Hareyama et al., 1991). Increased expression of the death receptor Fas following radiation has also been demonstrated in a 
transgenic carcinoembryonic antigen-expressing tumor model and associated with greater susceptibility to CTL mediated tumor cell lysis (Chakraborty et al., 2003). Combining immunotherapy and radiation building upon the hypothesis that radiation can enhance anti-tumor immunity, investigators have begun to combine radiation therapy with immunotherapies as was recently reviewed (Demaria et al., 2005a). Generally, such efforts employ radiation to induce tumor cell apoptosis or necrosis with resultant antigen release for subsequent presentation by DCs. Several investigators have studied combinations of intra-tumoral or peri-tumoral DC administration (Nikitina and), or administration of Flt-3L (Chakravarty et al., 1999, 2006; Demaria et al., 2004) combined with irradiation, yielding promising results. Administration of a recombinant viral vaccine-expressing tumorassociated antigen(s) and costimulatory molecules in combination with tumor irradiation may capitalize on the capacity of radiation to enhance immune recognition of antigenexpressing tumor cells. Such an effect was recently demonstrated and linked to radiation induced up regulation of Fas on tumor cells (Chakraborty et al., 2004). A number of investigators have explored combinations of cytokine therapy and irradiation; studied cytokines include IL-3 (Chiang et al., 2000), IL-12 (Seetharam et al., 1999; Lohr et al., 2000) and TNFa (Weichselbaum et al., 1994). Local radiation therapy in combination with CTLA-4 blockade is an additional novel approach for overcoming mechanisms of tumor tolerance. This combination was recently demonstrated to induce anti-tumor CD8 T cells in a poorly immunogenic murine adenocarcinoma model, whereas CTLA-4 blockade alone did not (Demaria et al., 2005b). Collectively, these studies encourage optimism regarding the potential of combined immunotherapy and radiotherapy.

The 'innate' components of the mammalian immune system has been reviewed and new concepts introduced; the discovery of Toll-like receptors (TLRs) is a notable example. These receptors recognize highly conserved molecular patterns common to pathogens, termed pathogen-associated molecular patterns (Janeway and Medzhitov, 2002). Examples of pathogen-associated molecular patterns and corresponding TLRs include:doublestranded RNA, which is recognized by TLR3 (Alexopoulou et al., 2001), Lipopolysaccharide (LPS), which is recognized by TLR4 (Poltorak et al., 1998) and many others (Roses et al., 2008).

An extensive investigation into the molecular basis of TLR function has been undertaken in recent years (Akira and Takeda, 2004). Though considerable overlap exists between implicated pathways, signaling through the various TLRs may initiate discreet downstream molecular events. Most TLRs act through the myeloid differentiation primary response protein 88 (MyD88) and tumor necrosis factor receptor-associated factor 6 to activate nuclear factor $\mathrm{kB}(\mathrm{NF}-\mathrm{kB})$ and mitogen-activated protein kinases and induce gene transcription. At the cellular level, TLR binding results not only in the activation of effectors of innate immunity, but also in the induction of adaptive responses. Ligation of TLRs expressed by antigen presenting cells may result in the expression of co-stimulatory molecules (for example, CD80 and CD86) and cytokines (for example, IL-6 and IL-12) (Macagno et al., 2007). Moreover, TLR-primed dendritic cells induce antigen-specific high avidity CD8 (Xu et al., 2003, 2006) and type-I polarized CD4 T-cell responses (Wesa et al., 2007). These findings have provided a foundation for immunotherapeutic strategies targeting tumor-associated antigens for the treatment of malignancies

Through the induction of antigen-presenting cell maturation and secretion of proinflammatory chemokines and cytokines, TLRs provide a link between innate and adaptive immunity, which may be exploited to induce robust immune responses against specific antigens, the therapeutic potential of TLR-targeted therapies. Conversely, TLR- 
targeted therapy may enhance subsequent responses to chemotherapy. Such combinations have been explored in a number of preclinical studies, sometimes with promising results (Lake and Robinson, 2005; Bourquin et al., 2006; Shi et al., 2007). While radiation therapy has not been explored as extensively, it too is emerging as a potentially powerful tool when combined with immunotherapies.

\section{Radiation-induced TLR signaling}

Investigations into the function TLRs have provided mechanistic insight into the actions of several established cancer therapies. Recent evidence suggests that TLR-dependent mechanisms contribute to the therapeutic effects of radiation as well. It has been widely hypothesized that tumor irradiation activates effectors of innate immunity through the induction of tumor cell apoptosis and the release of endogenous TLR agonists. The observation that such ubiquitous factors heat-shock proteins and uric acid can act through TLRs and induce DC maturation (Gallucci et al., 1999) supports this mechanism as does the demonstration that immature DCs, when administered into irradiated tumors, induce antitumor immunity (Kim et al., 2004).Most recently, the high-mobility-group box 1 alarmin protein, released by dying tumor cells, was shown to act on TLR4 expressed by DCs. Moreover, binding of TLR4 was demonstrated to increase the efficiency of tumor antigen processing and presentation (Apetoh et al., 2007). TLR dependent mechanisms may play a role in systemic therapies as well. Whole body irradiation was recently shown to increase bacterial translocation and circulating levels of the TLR 4 agonist lipopolysaccharide. This phenomenon was associated with enhanced anti-tumor immunity in an adoptive transfer model (Paulos et al., 2007). When considered together, such evidence provides a strong rationale for the use of radiation therapy as an immune intervention; a paradigm shift from the traditional view of radiation therapy as a cytotoxic therapy. The capacity of radiation to elicit the expression of TLR ligands systemically after gastrointestinal tract irradiation, or locally after tumor irradiation, may prove valuable in conjunction with other immunotherapies.

Potentiating anti-tumor immunity with radiation therapy and TLR agonists

Few investigators have directly studied the combination of radiation and TLR-targeted therapies; this despite recognition that the therapeutic effects of radiation maybe dependent upon TLR signaling. Mason et al. (2005) recently demonstrated a markedly enhanced tumor response to radiation therapy following peri- and intratumoral injections of the TLR agonist, CpG, in a murine fibrosarcoma model (Milas et al., 2004). In light of the recently elucidated role of TLRs in radiation induced responses, this effect may reflect synergy at the level of TLR signaling. Further investigations are required to determine the applicability of such approaches but potential implications of these findings are broad. TLR-targeted therapy may sensitize a wide range of tumor types to radiation therapy and result in a reduction of the radiation dose necessary to achieve a therapeutic effect. Such approaches may become increasingly important as new TLR-targeted therapies emerge.

\section{Conclusions}

Definitely, radiotherapy has been seen now as a immunomodulatory treatment. Many concepts has been changing during the past few years. A role for novel neoadjuvant immunotherapies is emerging and will result in opportunities to study their interplay with 
conventional treatments, such as chemotherapy and radiation and immunosuppressive drugs. Radiation therapy may be an important adjunct to immunotherapies with the potential to enhance the antigenicity of tumors and promote stromal targeting. Perhaps more importantly, radiation therapy may activate effectors of innate immunity through TLR-dependent mechanisms. The relative contributions of these distinct radiation-induced mechanisms remain unclear. As we learn more about the immune-mediated mechanisms we will be better able to utilize these modalities and emerging immunotherapies in combination (Roses et al, 2008).

\section{References}

Acker, J.C.; Marks, L.B.; Spencer, D.P.; et al. (1998). Serial in vivo observations of cerebral vasculature after treatment with a large single fraction of radiation. Radiat Res 149:350-359.

Akira, S. \& Takeda, K. (2004). Toll-like receptor signalling. Nat Rev Immunol 4:499-511.

Alexopoulou, L.; Holt, A.C.; Medzhitov, R; et al. (2001). Recognition of double-stranded RNA and activation of NF-kappaB by Toll-like receptor 3. Nature 413:732-738.

Antony, P.A; Piccirillo, C.A; Akpinarli, A, et al. (2005). CD8+ T cell immunity against a tumor/self-antigen is augmented by CD4+ T helper cells and hindered by naturally occurring T regulatory cells. J Immunol 174: 2591-2601.

Apetoh, L.; Ghiringhelli, F; Tesniere, A.; et al. (2007). Toll-like receptor 4-dependent contribution of the immune system to anticancer chemotherapy and radiotherapy. Nat Med 13:1050-1059.

Basu, S.; Binder R.J.; Suto, R.;et al. (2000). Necrotic but not apoptotic cell death releases heat shock proteins, which deliver a partial maturation signal to dendritic cells and activate the NF-kappa B pathway. Int Immunol 12:1539-1546.

Bayer, A.L.; Jones, M.; Chirinos, J.; et al. (2009) Host CD4+CD25+ T cells can expand and comprise a major component of the Treg compartment after experimental HCT. Blood; 113:733-43.

Bourquin, C.; Schreiber, S.; Beck, S. ; et al. (2006). Immunotherapy with dendritic cells and $\mathrm{CpG}$ oligonucleotides can be combined with chemotherapy without loss of efficacy in a mouse model of colon cancer. Int J Cancer 118:2790-2795.

Belka, C.; Ottinger, H.; Kreuzfelder, E.; et al. (1999). Impact of localized radiotherapy on blood immune cells counts and function in humans. Radiotherapy \& Oncology, 50:199-204.

Cao, M.D.; Chen, Z.D.; Xing, Y. (2004). Gamma irradiation of human dendritic cells influences proliferation and cytokine profile of $\mathrm{T}$ cells in autologous mixed lymphocyte reaction. Cell Biol Int 28:223-228.

Cao, Z.A.; Daniel, D.; Hanahan D. (2002). Sub-lethal radiation enhances anti-tumor immunotherapy in a transgenic mouse model of pancreatic cancer. BMC Cancer 2:11.

Cao, M.; Cabrera, R.; Xu, Y; et al. (2009). Gamma irradiation alters phenotypes and function of CD4pCD25p regulatory T cells. Cell Biology International 33:565-571.

Chai, J.G.; Xue, S.A.; Coe D.; et al. (2005) Regulatory T cells, derived from naiveCD4+CD25$\mathrm{T}$ cells by in vitro Foxp3 gene transfer, can induce transplantation tolerance. Transplantation; 79(10):1310-1316. 
Chakraborty, M.; Abrams, S.I.; Camphausen, K.; et al. (2003). Irradiation of tumor cells upregulates Fas and enhances CTL lytic activity and CTL adoptive immunotherapy. J Immunol 170:6338-6347.

Chakravarty, P.K.; Alfieri, A.; Thomas, E.K.; et al. (1999). Flt3-ligand administration after radiation therapy prolongs survival in a murine model of metastatic lung cancer. Cancer Res 59:6028-6032.

Chakravarty, P.K.; Guha, C.; Alfieri, A. et al. (2006). Flt3L therapy following localized tumor irradiation generates long-term protective immune response in metastatic lung cancer:its implication in designing a vaccination strategy. Oncology 70:245-254.

Chiang, C.S.; Hong, J.H.; Wu, Y.C.; et al. (2000). Combining radiation therapy with interleukin-3 gene immunotherapy. Cancer Gene Ther 7:1172-1178.

Cole, S. (1986). Long-term effects of local ionizing radiation treatment on Langerhans cells in mouse footpad epidermis. J Invest Dermatol, 87:608-612.

Cox, A.L., Thompson, S.A., Jones, J.L., et al. (2005) Lymphocyte homeostasis following therapeutic lymphocyte depletion in multiple sclerosis. Eur J Immunol ;35:33323342.

Dazzi, F.; van Laar J.M.; Cope, A.; et al. (2007) Cell therapy for autoimmune diseases. Arthritis Res Ther 2007;9:206.

Demaria, S.; Ng B.; Devitt, M.L.; et al. (2004). Ionizing radiation inhibition of distant untreated tumors (abscopal effect) is immune mediated. Int J Radiat Oncol Biol Phys 58:862-870.

Demaria, S.; Bhardwaj, N.; McBride, W.H.; et al. (2005a). Combining radiotherapy and immunotherapy:a revived partnership. Int J Radiat Oncol Biol Phys 63:655-666.

Demaria, S.; Kawashima, N.; Yang, A.M.; et al. (2005b). Immune-mediated inhibition of metastases after treatment with local radiation and CTLA- 4 blockade in a mouse model of breast cancer. Clin Cancer Res 11:728-734.

Dunn, P.L. \& North RJ. (1991). Selective radiation resistance of immunologically induced T cells as the basis for irradiationinduced T-cell-mediated regression of immunogenic tumor. J Leukoc Biol 49:388-396.

Durham, M.M.; Bingaman, A.W.; Adams, A.B.; et al.(2000) Cutting edge: administration of anti-CD40 ligand and donor bone marrow leads to hemopoietic chimerism and donor-specific tolerance without cytoreductive conditioning. J Immunol;165(1):1-4.

Dutt, S.; Tseng, D.; Ermann, J.; et al.(2007) Naive and memory T cells induce different types of graft-versus-host disease. J Immunol 2007;179(10):6547-6554.

Ferguson, R.M.; Sutherland D.E.R.; Kim, T., et al (1981) The in vitro assessment of the immunosuppressive effect of fractionated total lymphoid irradiation in renal allotransplantation. Transplant Proc, 3:1673-1675.

Finkel, T. (1998). Oxygen radicals and signaling. Current Opinion in Cell Biology, 10:248253.

Fudaba, Y.; Spitzer ,T.R.; Shaffer, J., et al.(2006) Myeloma responses and tolerance following combined kidney and nonmyeloablative marrow transplantation: in vivo and in vitro analyses. Am J Transplant ;6(9):2121-2133.

Fujimoto M, Serada S, Mihara M, et al (2008) Interleukin-6 blockade suppresses autoimmune arthritis in mice by the inhibition of infl ammatory Th17 responses. Arthritis Rheum; 58:3710-9. 
Gallucci, S. ; Lolkema, M. ; Matzinger, P. (1999). Natural adjuvants:endogenous activators of dendritic cells. Nat Med 5:1249-1255.

Golshayan, D.; Jiang, S.; Tsang, J.; et al.(2007) In vitro-expanded donor alloantigenspecific $\mathrm{CD} 4+\mathrm{CD} 25+$ regulatory $\mathrm{T}$ cells promote experimental transplantation tolerance. Blood;109(2):827-835.

Graca L, Cobbold SP, Waldmann H. (2002) Identification of regulatory T cells in tolerated allografts. J Exp Med ;195(12):1641-1646.

Graca, L., Daley, S., Fairchild, P.J.,et al. (2006) . Co-receptor and co-stimulation blockade for mixed chimerism and tolerance without myelosuppressive conditioning. BMC Immunol;7:9.

Gray, C.M; Smit Jam; Myburgh J.A (1989): Function and Numbers of natural killer (NK) cells in patients conditioned with total lymphoid irradiation (TLI). Tranplant Proc; 21(1):1980-1981.

Hallahan, D.E. \& Virudachalam, S. (1999). Accumulation of P-selectin in the lumen of irradiated blood vessels. Radiat Res 152:6-13.

Hallahan, D.E.; Spriggs, D.R.; Beckett, M.A et al. (1989). Increased tumor necrosis factor alpha mRNA after cellular exposure to ionizing radiation. Proc Natl Acad Sci USA 86:10104-10107.

Hashimoto, S.; Shirato, H.; Hosokawa, M.; et al. (1999). The suppression of metastases and the change in host immune response after low-dose total-body irradiation in tumor-bearing rats. Radiation Research, 151:717-724.

Hauser SH, Calorini L, Wazer DE; et al. (1993). Radiation-enhanced expression of major histocompatibility complex class I antigen $\mathrm{H}-2 \mathrm{Db}$ in B16 melanoma cells. Cancer Res 53:1952-1955.

Hayamizu, K.; Lan, F.; Huie, P., Sibley,R.K.; et al. (1999) Comparison of chimeric acid and non-chimeric tolerance using posttransplant total lymphoid irradiation: cytokine expression and chronic rejection.Transplantation ;68(7):1036-1044.

Higuchi, M.; Zeng, D.; Shizuru, J.; et al. (2002). Immune tolerance to combined organ and bone marrow transplants after fractionated lymphoid irradiation involves regulatory NK T cells and clonal deletion. J Immunol 2002;169(10):5564-5570.

Hoffmann P, Boeld TJ, Eder R, et al. (2009) Loss of FOXP3 expression in natural human $\mathrm{CD} 4+\mathrm{CD} 25+$ regulatory $\mathrm{T}$ cells upon repetitive in vitro stimulation. Eur J Immunol ;39:1088-97.

Ildstad ST, Sachs DH (1984). Reconstitution with syngeneic plus allogeneic or xenogeneic bone marrow Leads to specific acceptance of allografts orxenografts. Nature;307(5947):168-170.

Ishihara, H., Tanaka, I.; Nemoto, K.; et al. (1995). Immediate-early, transient induction of the interleukin-1 beta gene in mouse spleen macrophages by ionizing radiation. $\mathrm{J}$ Radiat Res (Tokyo) 36:112-124.

Janeway Jr, C.A. \& Medzhitov, R. (2002). Innate immune recognition. Annu Rev Immunol 20:197-216.

James,R.F.; Lake, S.P.; Chamberlain J., et al. (1989). Gamma irradiation of isolated rat islets pretransplantation produces indefinite allograft survival in cyclosporinetreatedrecipients. Transplantation, 47:929-933. 
Jin, S.Z.; Pan, X.N.; Wu N.; et al. (2007). Whole-body low dose irradiation promotes the efficacy of conventional radiotherapy for cancer and possible mechanisms. Dose Response 5:349-358.

Jonathan, E.C.; Bernhard, E.J; McKenna, W.G. (1999). How does radiation kill cells? Current Opinion in Chemical Biology, 3:77-83.

Kang,S.M.; Tang, Q.; Bluestone, J.A. (2007)CD4+CD25+ regulatory T cells in transplantation: progress, challenges and prospects. Am J Transplant ;7(6):1457-1463.

Kasid, U.; Suy, S.; Dent, P., et al. (1996). Activation of Raf by ionizing radiation. Nature, 382:813-816.

Kawai, T.; Cosimi, A.B; Wee, S.L.; et al. (2002). Effect of mixed hematopoietic chimerism on cardiac allograft survival in cynomolgus monkeys.Transplantation ; 73(11):17571764 .

Kawai T.; Cosimi A.B.; Spitzer, T.R.; et al (2008). HLA mismatchedrenal transplantation without maintenance immunosuppression. N Engl J Med 2008;358 (4):353-361.

Kim, K.W.; Kim, S.H.; Shin, J.G.; et al. (2004). Direct injection of immature dendritic cells into irradiated tumor induces efficient antitumor immunity. Int J Cancer 109:685690.

Kipnis, J.; Avidan, H.; Markovich, Y.; et al. (2004). Low-dose gamma-irradiation promotes survival of injured neurons in the central nervous system via homeostasis-driven proliferation of T cells. European Journal of Neuroscience 19:1191-1198.

Lake, R.A. \& Robinson, B. W. (2005). Immunotherapy and chemotherapy - a practical partnership. Nat Rev Cancer 5: 397-405.

Lambert, J.F., Colvin, G.A.; Zhong S., et al (2002). H2-mismatched transplantation with repetitive cell infusions and CD40 ligand antibody infusions without myeloablation. Br J Haematol ;119(1):155-163.

Lan F, Hayamizu K, Strober S (2000). Cyclosporine facilitates chimeric and inhibits nonchimeric tolerance after posttransplant total lymphoid irradiation. Transplantation;69(4):649-655.

Lander, H.M.; Tauras, J.M.; Ogiste, J.S., et al(1997). Activation of the receptor for advanced glycation end products triggers a p21(ras)-dependent mitogen-activated protein kinase pathway regulated by oxidant stress. Journal of Biological Chemistry, 272:17810-17814.

Laylor R, Dewchand H, Simpson E, et al. (2005). Engraftment of allogeneic hematopoietic stem cells requires both inhibition of host-versus-graft responses and 'space' for homeostatic expansion. Transplantation;79:1484-91.

Liao , Y.P.; Wang, C.C.; Butterfield, L.H.; et al. (2004). Ionizing radiation affects human MART-1 melanoma antigen processing and presentation by dendritic cells. J Immunol 173:2462-2469.

Liu, R.; Xiong, S.; Zhang, L.; et al.( 2010). Enhancement of antitumor immunity by low-dose total body irradiationis associated with selectively decreasing the proportion and number of T regulatory cells. Cellular \& Molecular Immunology, 7:157-162.

Liu, S.Z.; Jin, S.Z; , Liu, X.D.; et al. (2001). Role of CD28/B7 costimulation and IL-12/IL-10 interaction in the radiationinduced immune changes. BMC Immunology 2:8.

Lohr, F.; Hu, K.; Haroon Z.; et al. (2000). Combination treatment of murine tumors by adenovirus-mediated local B7/IL12 immunotherapy and radiotherapy. Mol Ther 2:195-203. 
Lohr, J.; Knoechel, B.; Wang, J.J.; et al (2006). Role of IL-17 and regulatory T lymphocytes in a systemic autoimmune disease. J Exp Med ;203:2785-91.

Macagno, A.; Napolitani, G.; Lanzavecchia, A. ; et al., (2007). Duration, combination and timing:the signal integration model of dendritic cell activation. Trends Immunol 28:227-233.

Mason, K.A.; Ariga, H. ; Neal, R. ; et al. (2005). Targeting toll-like receptor 9 with CpG oligodeoxynucleotides enhances tumor response to fractionated radiotherapy. Clin Cancer Res 11:361-369.

Mcbride, W.H.; Chiang, C.S.; Olson, J.L, et al (2004). A sense of danger from radiation. Radiat Res 2004, 162:1-19.

Mengde, C., et al. (2011). Different radiosensitivity of CD4pCD25p regulatory T cells and effector T cells to low dose gamma irradiation in vitro. Int. J. Radiat. Biol., 87(1) : 71-80.

Merrick, A.; Errington, F.; Milward, K.; et al. (2005). Immunosuppressive effects of radiation on human dendritic cells:reduced IL-12 production on activation and impairment of naive T-cellpriming. Br J Cancer 92:1450-1458.

Milas, L.; Mason, K.A.; Ariga, H. ; et al. (2004). CpG oligodeoxynucleotide enhances tumor response to radiation. Cancer Res 64:5074-5077.

Miller GM, Kim DW, Andres ML; et al. (2003). Changes in the activation and reconstitution of lymphocytes resulting from total-body irradiation correlate with slowed tumor growth. Oncology 65:229-241.

Minamimura, K., Gao, W., Maki, T. (2006) CD4+ regulatory T cells are spared from deletion by antilymphocyteserum, a polyclonal anti-T cell antibody.J Immunol;176(7):41254132.

Morgan ME, Sutmuller RP, Witteveen HJ, et al.(2003) CD25+ cell depletion hastens the onset of severe disease in collagen-induced arthritis. Arthritis Rheum ;48:1452-60.

Morgan ME, Flierman R, van Duivenvoorde LM, et al. (2005) Effective treatment of collageninduced arthritis by adoptive transfer of CD25+ regulatory T cells. Arthritis Rheum 52:2212-21.

Muraro, P.A., Douek, D.C., Packer, A.; et al (2005). Thymic output generates a new and diverse TCR repertoire after autologous stem cell transplantation in multiple sclerosis patients. J Exp Med 2005;201:805-16.

Nadal E, Garin M, Kaeda J, et al (2007) Increased frequencies of CD4(+)CD25(high) T(regs) correlate with disease relapse after allogeneic stem cell transplantation for chronic myeloid leukemia. Leukemia ;21:472-9.

Nadkarni S, Mauri C, Ehrenstein MR.(2007) Anti-TNF-alpha therapy induces a distinct regulatory $\mathrm{T}$ cell population in patients with rheumatoid arthritis via TGF-beta. J Exp Med;204:33-9.

Nador, R.G; Hongo, D; Yao, Z et al.; (2010) The Changed Balance of Regulatory and Naive T Cells Promotes Tolerance After TLI and Anti-T Cell Antibody Conditioning. Am J Transplant.; 10(2): 262-272.

Nakatsukasa H, Tsukimoto M, Ohshima Y, et al. (2008) Suppressing effect of low-dose gamma-ray irradiation on collagen-induced arthritis. J Radiat Res 2008;49:381-389.

Nemoto K, Ishihara, H., Tanaka, I.; et al. (1995). Expression of IL-1 beta mRNA in mice after whole body X-irradiation. J Radiat Res (Tokyo) 36:125-133. 
Nikitina EY, Gabrilovich DI. (2001). Combination of gammairradiation and dendritic cell administration induces apotent antitumor response in tumor-bearing mice:approach to treatment of advanced stage cancer. Int J Cancer 94: 825-833.

North RJ. (1986). Radiation-induced, immunologicallymediated regression of an established tumor as an example of successful therapeutic immunomanipulation Preferential elimination of suppressor T cells allows sustained production of effector T cells. J Exp Med 164: 1652-1666.

Notley CA, Inglis JJ, Alzabin S, et al. (2008). Blockade of tumor necrosis factor in collageninduced arthritis reveals a novel immunoregulatory pathway for Th1 and Th17 cells. J Exp Med;205:2491-2497.

Paulos, C.M.; Wrzesinski, C.; Kaiser, A., et al. (2007). Microbial translocation augments the function of adoptively transferred self/tumor-specific CD8 T cells via TLR4 signaling. J Clin Invest 117: 2197-2204.

Pillai, A.B.; George, T.I., Dutt, S.; et al. (2009) Host natural killer T cells induce an IL-4 dependent expansion of donor CD4+CD25+Foxp3+ Tregs that protects against graft-versus-host disease. Blood.

Poltorak, A.; He, X.; Smirnova, I.; et al. (1998). Defective LPS signaling in C3H/HeJ and C57BL/10ScCr mice:mutations in Tlr4 gene. Science 282: 2085-2088.

Reuben JM; Korbling M; Gao H, et al.; (2004). The effect of low dose gamma irradiation on the differentiation and maturationof monocyte derived dendritic cells. Journal of Gravitational Physiology 11:P49-52.

Rho, H.S.; Park S.S.; Lee, C.E. (2004). Gamma irradiation up-regulatesexpression of B cell differentiation molecule CD23 by NFkappaB activation. Journal of Biochemistry and Molecular Biology 37:507-514.

Roord ST, de Jager W, Boon L, et al.(2008) Autologous bone marrow transplantation in autoimmune arthritis restores immune homeostasis through CD4+CD25+Foxp3+ regulatory T cells. Blood;111:5233-41.

Roses R E; Xu M; Koski GK; et al. (2008). Radiation therapy and Toll-like receptor signaling: Implications for the treatment of cancer. Oncogene 27:200-207.

Safwat A. (2000a). The immunobiology of low-dose total-body irradiation: More questions than answers. Radiation Research 153(5 Pt 1):599-604.

Safwat A.( 2000b). The role of low-dose total body irradiation in treatment of non-hodgkin's lymphoma: A new look at an old method. Radiotherapy \& Oncology 56:1-8.

Sakaguchi N, Takahashi T, Hata H, et al. (2003) Altered thymic T-cell selection due to a mutation of the ZAP-70 gene causes autoimmune arthritis in mice. Nature;426:45460.

Sakaguchi S. (2005) Naturally arising Foxp3-expressing CD25+CD4+ regulatory T cells in immunological tolerance to self and non-self. Nat Immunol 2005;6(4):345-352.

Sauter B, Albert ML, Francisco L.; et al. (2000). Consequences of cell death:exposureto necrotic tumor cells, but not primary tissue cells orapoptotic cells, induces the maturation of immunostimulatory dendritic cells. J Exp Med 191:423-434.

Seetharam, S.; Staba, M.J.; Schumm, L.P. ; et al. (1999). Enhanced eradication of local and distant tumors by genetically produced interleukin-12 and radiation. Int J Oncol 15:769-773.

Scandling, J.D.; Busque S.; Dejbakhsh-Jones S.; et al (2008). Tolerance and chimerism after renal and hematopoietic-cell transplantation. N Engl J Med 2008;358(4):362-368. 
Scheffer SR, Nave H, Korangy F, et al. (2003). Apoptotic, but not necrotic, tumor cell vaccines induce a potent immune response in vivo. Int J Cancer 103:205-211.

Schiopu, A. \& Wood, K.J. (2008) Regulatory T cells: hypes and limitations. Curr Opin Organ Transplant 2008;13 (4):333-338.

Schu“ tze S.; Tchikov, V.; Schneider-Brachert, W. (2008). Regulation of TNFR1 and CD95 signalling by receptor compartmentalization. Nature Reviews. Molecular Cell Biology 9:655-662.

Shan, Y.X.; Jin, S.Z.; Liu, X.D.; et al. (2007). Ionizing radiation stimulates secretion of proinflammatory cytokines: Dose response relationship, mechanisms and implications.Radiation and Environmental Biophysics 46:21-29.

Shankar, B.; Premachandran, S.; Bharambe, S.D.; et al. (1999). Modification of immune response by low dose ionizing radiation: Role of apoptosis. Immunology Letters 68:237-245.

Shi, Y.; White, D.; He, L. ; et al.; (2007). Toll-like receptor-7 tolerizes malignant B cells and enhances killing by cytotoxic agents. Cancer Res 67:1823-1831.

Shigematsu, A., Adachi, Y., Koike-Kiriyama, N., et al. (2007). Effects of low- dose irradiation on enhancement of immunity by dendritic cells. J Radiat Res (Tokyo) 48:51-55.

Slavin S, Strober S, Fuks Z (1977), et al. Induction of specific tissue transplantation tolerance using fractionated total lymphoid irradiation in adult mice: long-term survival of allogeneic bone marrow and skin grafts. J Exp Med;146(1):34-48.

Slavin, S.; Reitz, B.; Bieber, C.P.; et al (1978). Transplantation tolerance in adult rats using total lymphoid irradiation: permanent survival of skin, heart, and marrow allografts. J Exp Med;147(3):700-707.

Slavin, S.; Strober, S.; Fuks, Z.; Kapla, H.S. (1976). Long-term survival of skin allografts in mice treated with fractionated total lymphoid irradiation. Science ;193(4259):12521254.

Sykes M. (2001) Mixed chimerism and transplant tolerance. Immunity 2001;14(4):417-42.

Tang Q, Henriksen $\mathrm{KJ}, \mathrm{Bi} \mathrm{M}$, et al. In vitro-expanded antigen-specifi c regulatory $\mathrm{T}$ cells suppress autoimmune diabetes. J Exp Med 2004;199:1455-65.

Villar, R.C.; Chocair, P.R.; Nadalin, W.; et al (2008). Total Lymphoid Irradiation for pretransplant immunossuppression and reccurrence of focal segmental glomerulosclerosis Transpl Int., Mar;21(3):286-9.

Waer, M.; Vanrenterghen, E.; Van der schueren, E., et al (1987). Identification and function of a major OKT3, OKT8, Leu-7, posiitve lymphocyte subpopulation in renal transplant recipients treated with total lymphoid irradiation. Transplant Proc 19(1):1570-1571.

Wasserman, J.; Blomgren, H; Rotstein, S; et al. (1989). Immunosuppression in irradiated breastcancer patients: in vitro effect of cyclooxygenase inhibitors. Bull N Y Acad Med, 65:36-44.

Wekerle T.; Sayegh, M.H.;Hill J.; et al.(1998) Extrathymic T cell deletion and allogeneic stem cell engraftment induced with costimulatory blockade is followed by central T cell tolerance. J Exp Med 187(12):2037-2044.

Wekerle, T.; Kurtz, J.; Ito, H.; et al. (2000) Allogeneic bone marrow transplantation with costimulatory blockade induces macrochimerism and tolerance without cytoreductive host treatment. Nat Med 2000;6(4):464-469. 
Weng L, Dyson J, Dazzi F. (2007) Low-intensity transplant regimens facilitate recruitment of donor- specific regulatory $\mathrm{T}$ cells that promote hematopoietic engraftment. Proc Natl Acad Sci USA;104:8415-20.

Weng, L.; Willians, O.S.; Vieira, P.L. et al., (2010). The therapeutic activity of low-dose irradiation on experimental arthritis depends on the induction of endogenous regulatory T cell activity Ann Rheum Dis 2010;69:1519-1526.

Weichselbaum, R.R.; Hallahan, D. E.; Beckett, M.A. ; et al. (1994). Gene therapy targeted by radiation preferentially radiosensitizes tumor cells. Cancer Res 54:4266-4269.

Wesa, A.; Kalinski, P.; Kirkwood, J.M. , et al. (2007). Polarized type-1 dendritic cells (DC1) producing high levels of IL-12 family members rescue patient TH1-type antimelanoma CD4+ T cell responses in vitro. J Immunother 30:75- 82.

Wing K, Fehervari Z, Sakaguchi S. (2006). Emerging possibilities in the development and function of regulatory T cells. International Immunology 18:991-1000.

Wood,K.J.; Sakaguchi, S. (2003). Regulatory T cells in transplantation tolerance. Nat Rev Immunol 2003;3(3):199-210.

Wrzesinski C, Paulos CM, Gattinoni L et al. (2007). Hematopoietic stem cells promote the expansion and function of adoptively transferred antitumor CD8 T cells. J Clin Invest 117:492-501.

Xiao X, Kroemer A, Gao W, et al. (2008) OX40/OX40L costimulation affects induction of Foxp3+ regulatory $\mathrm{T}$ cells in part by expanding memory $\mathrm{T}$ cells in vivo. $\mathrm{J}$ Immunol;181:3193-201.

Xu, S.; Koski, G. K. ; Maeurer, M.; et al. (2003). Rapid high efficiency sensitization of CD8+ $\mathrm{T}$ cells to tumor antigens by dendritic cells leads to enhanced functional avidity and direct tumor recognition through an IL-12-dependent mechanism. J Immunol 171:2251-2261.

Yao, Z.; Liu, Y.; Jones, J.; Strober, S. (2009). Differences in Bcl-2 expression by T-cell subsets alter their balance after in vivo irradiation to favor CD4+Bcl-2hi NKT cells. Eur J Immunol;39(3):763-775.

Zhang, B.; Bowerman, N. A., Salama, J.K., et al. (2007). Induced sensitization of tumor stroma leads to eradication of established cancer by T cells. J Exp Med 204:49-55.

Zou W. (2006) . Regulatory T cells, tumour immunity and immunotherapy. Nature Reviews. Immunology 6:295-307. 


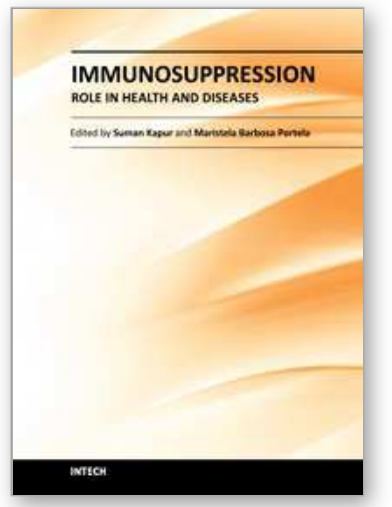

\author{
Immunosuppression - Role in Health and Diseases \\ Edited by Dr. Suman Kapur
}

ISBN 978-953-51-0152-9

Hard cover, 470 pages

Publisher InTech

Published online 24, February, 2012

Published in print edition February, 2012

A need for a book on immunology which primarily focuses on the needs of medical and clinical research students was recognized. This book, "Immunosuppression - Role in Health and Diseases" is relatively short and contains topics relevant to the understanding of human immune system and its role in health and diseases. Immunosuppression involves an act that reduces the activation or efficacy of the immune system. Therapeutic immunosuppression has applications in clinical medicine, ranging from prevention and treatment of organ/bone marrow transplant rejection, management of autoimmune and inflammatory disorders. It brings important developments both in the field of molecular mechanisms involved and active therapeutic approaches employed for immunosuppression in various human disease conditions. There was a need to bring this information together in a single volume, as much of the recent developments are dispersed throughout biomedical literature, largely in specialized journals. This book will serve well the practicing physicians, surgeons and biomedical scientists as it provides an insight into various approaches to immunosuppression and reviews current developments in each area.

\title{
How to reference
}

In order to correctly reference this scholarly work, feel free to copy and paste the following:

Rosangela Correa Villar (2012). Radiotherapy and Immunity - A Mini Review, Immunosuppression - Role in Health and Diseases, Dr. Suman Kapur (Ed.), ISBN: 978-953-51-0152-9, InTech, Available from: http://www.intechopen.com/books/immunosuppression-role-in-health-and-diseases/total-lymphoid-irradiationfor-pretransplant-immunosuppression-mini-review

\section{INTECH}

open science | open minds

\section{InTech Europe}

University Campus STeP Ri

Slavka Krautzeka 83/A

51000 Rijeka, Croatia

Phone: +385 (51) 770447

Fax: +385 (51) 686166

www.intechopen.com

\section{InTech China}

Unit 405, Office Block, Hotel Equatorial Shanghai

No.65, Yan An Road (West), Shanghai, 200040, China 中国上海市延安西路65号上海国际贵都大饭店办公楼 405 单元

Phone: +86-21-62489820

Fax: +86-21-62489821 
(C) 2012 The Author(s). Licensee IntechOpen. This is an open access article distributed under the terms of the Creative Commons Attribution 3.0 License, which permits unrestricted use, distribution, and reproduction in any medium, provided the original work is properly cited. 